\title{
O JARDIM VENENOSO: A QUÍMICA POR TRÁS DAS INTOXICAÇÕES DOMÉSTICAS POR PLANTAS
} ORNAMENTAIS

\author{
Ana Tayná Chaves Aguiar ${ }^{\mathrm{a}}$ e Valdir Florêncio da Veiga Júnior*a, \\ ${ }^{a}$ Seção de Química, Instituto Militar de Engenharia, 22270-290 Rio de Janeiro - RJ, Brasil
}

Recebido em 24/11/2020; aceito em 04/03/2021; publicado na web em 01/04/2021

\begin{abstract}
THE POISONOUS GARDEN: THE CHEMISTRY BEHIND THE INTOXICATION BY DOMESTIC ORNAMENTAL PLANTS. In times of the COVID-19 pandemic, despite the fact families have spent more time together, the job demands and commitments that adults have now brought into their homes may mean their attention has been taken away from their children. This, combined with the absence of older family members or domestic helpers that assist in looking after the children has left them potentially more exposed to domestic accidents. Data from the National Toxic-Pharmacological Information System indicate that two-thirds of domestic intoxications with plants (usually the ornamental ones) occur in children. These accidents can be caused either by inhalation, contact with the skin, eyes and mucous membranes, as well as by ingestion. The toxicity of ornamental plants is due to the presence of substances such as oxalic acid and its highly irritating salts, alkaloids, glycosides, flavonoids, and toxic terpenes, among several other classes of secondary metabolites. In the present study, we carried out a survey of the main ornamental plants used in the country and analyzed the toxic substances that can cause numerous conditions from dermatitis in milder cases to death in more severe cases.
\end{abstract}

Keywords: ornamental plants; domestic intoxication; specialized metabolites; calcium oxalate.

\section{INTRODUÇÃO}

As características de diversas plantas tóxicas brasileiras já eram de conhecimento tradicional da população. Com a experiência empírica, aprenderam como tornar a mandioca comestível (retirando o cianeto), como capturar peixes liberando na água substâncias tóxicas (as rotenonas) de plantas como o timbó, e como empregar venenos (os alcaloides tubocurarínicos) nas pontas das flechas para imobilizar os animais, sem torná-los impróprios ao consumo. Nos relatos do botânico Barbosa Rodrigues, os indígenas aprenderam observando animais como os gaviões, que esfregavam as garras nas árvores do veneno antes de caçar, imobilizando as presas rapidamente..$^{1,2}$

Botânicos famosos que estiveram no Brasil com os primeiros exploradores, como André Thévet, já relatavam o uso de plantas ornamentais e tóxicas. Naturalista que veio na frota de Villegagnon para a instalação da França Antártica no Rio de Janeiro, em 1555, Thévet observou uma espécie cujos frutos de formato muito peculiar (mais tarde conhecida popularmente como Chapéu-deNapoleão) eram utilizados pelos índios Tamoios como adereços ornamentais, em chocalhos nos tornozelos que chamavam "Aouaí". Observou também os efeitos tóxicos da infusão dessa planta, uma Apocynaceae, denominada Thevetia ahouai em sua homenagem. O chá era empregado para o assassinato do cônjuge, utilizado pelos casais nos casos de adultério. Mais tarde relacionou-se a ação tóxica a glicosídeos cardiotóxicos, como a cerberina. ${ }^{2}$

Um dos estudos nacionais mais antigos e completos buscando relacionar a toxicidade das espécies vegetais com suas substâncias químicas foi realizado pelo botânico mineiro Frederico Carlos Hoehne, em 1939. ${ }^{2}$ Destinado a químicos, médicos e veterinários, seu livro tem foco nas plantas medicinais e naquelas tóxicas para os rebanhos. Aparecem com destaque os riscos de plantas tóxicas que são também medicinais, as que produzem metabólitos tóxicos só em períodos específicos de seu desenvolvimento e ainda as que não possuem efeitos agudos no consumo, mas cuja ingestão excessiva gera efeitos crônicos. Hoehne já apontava a toxicidade de diversas

*e-mail: valdir.veiga@gmail.com plantas ornamentais, como o Algodão-do-Brejo (Ipomoea fistulosa), gênero rico em alcaloides.

A conscientização ambiental crescente estimula o uso de plantas ornamentais na decoração de ambientes internos. O confinamento forçado estabelecido pelos governos para controlar a disseminação da COVID-19 tem deixado as famílias em seus lares por períodos muito maiores, aumentando as preocupações com a falta de supervisão das crianças que estão em tempo integral em casa, com seus pais concentrados no trabalho remoto e sem o auxílio de outros adultos, também em isolamento. Nessa situação, o contato com as plantas ornamentais é potencializado e o reconhecimento de quais plantas são tóxicas e quais são os seus riscos passa a ser ainda mais importante. Neste artigo foi realizado um levantamento bibliográfico das principais plantas tóxicas utilizadas com fins ornamentais no país e são apresentadas as substâncias causadoras destes efeitos.

\section{Intoxicação com plantas no Brasil}

As espécies ornamentais são escolhidas por seu perfume e beleza, mas também por fatores culturais e até religiosos, o que torna o ambiente doméstico bastante variável de país para país, não somente por sua flora autóctone, mas pelos costumes, usos e saberes tradicionais. A imensa biodiversidade vegetal, o desejo por estar próximo à natureza, um privilegiado senso de estética, a miscigenação cultural e o sincretismo religioso são fatores que estimulam a presença de diferentes espécies vegetais nos lares dos brasileiros. Belas, coloridas, aromáticas, para afastar mal olhado, oferecidas aos deuses ou para proteção, muitas dessas nossas plantas ornamentais mais comuns (Figura 1) são potencialmente prejudiciais à saúde de humanos e seus animais domésticos devido à presença de toxinas que podem ser tóxicas por ingestão, contato ou até mesmo inalação. Diversos estudos atuais têm avaliado as plantas tóxicas presentes nos lares brasileiros e a importância de se ter o conhecimento sobre tais plantas, como forma de prevenção contra possíveis acidentes. ${ }^{3-8}$

De acordo com os dados do Sistema Nacional de Informações Tóxico-Farmacológicas (SINITOX), as principais vítimas de intoxicação por plantas são crianças de 0 a 14 anos de idade 


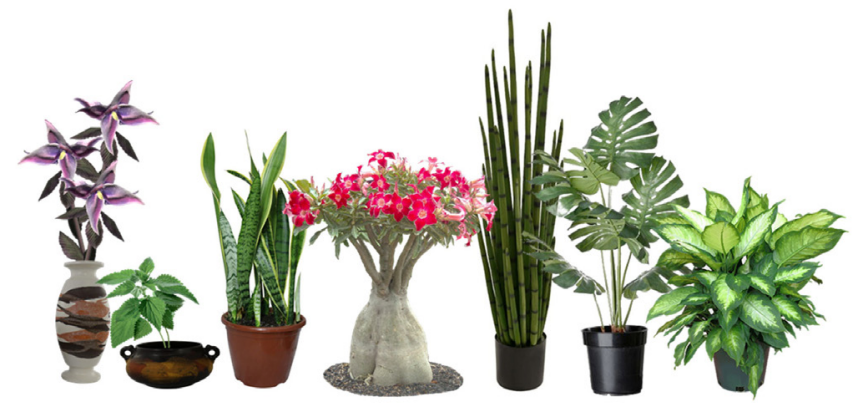

Figura 1. Principais plantas ornamentais tóxicas observadas nos lares brasileiros (da esquerda para direita): Atropa belladona, Urtica dioica, Sansevieria trifasciata, Adenium obesum, Sansevieria cylindrica, Monstera deliciosa e Dieffenbachia picta

(Figura 2), ${ }^{9}$ que representam dois terços dos casos de intoxicações em humanos (6,6\% dos casos relatados são em animais domésticos). A cada dez casos de intoxicação por plantas no Brasil, seis são de crianças menores de nove anos de idade, sendo em sua maioria casos acidentais, principalmente por não haver o conhecimento prévio dos responsáveis sobre o potencial tóxico das espécies utilizadas. ${ }^{10}$ O contato de crianças com estas espécies vegetais tóxicas pode ser residencial, mas também ocorre muito frequentemente em outros ambientes. Em um estudo realizado em 85 jardins de infância e centros de cuidados para crianças observou-se que $31 \%$ das plantas analisadas eram potenciais causadoras de injúrias. ${ }^{11}$

As regiões brasileiras que apresentam mais casos de intoxicação por plantas são a Sul e a Sudeste (Figura 3). ${ }^{9}$ Analisando-se a incidência dos registros com o percentual da população por região, observa-se que apesar do Sudeste apresentar maior número de registros, esse percentual $(40,8 \%)$ está de acordo com o percentual da população brasileira que habita esta região $(42,0 \%)$, estimado pelo IBGE para $2020 .{ }^{12}$ Estudo realizado em apenas um bairro na região de Miguelópolis, em São Paulo, identificou 72 plantas tóxicas na ornamentação urbana, sendo a mais frequente a Dieffenbachia picta (Araceae), conhecida popularmente pela nome Comigo-Ninguém-Pode. ${ }^{13}$

A incidência de acidentes é bem maior na Região Sul, uma vez que apenas $14,3 \%$ da população está nessa região. No CentroOeste, os acidentes $(11,6 \%)$ também têm incidência maior que o percentual da população na região $(7,8 \%)$. Com cerca de $3-4$ vezes menos acidentes que o percentual da população da região, o Norte e o Nordeste são também as regiões brasileiras em que menos de $80 \%$ da população está nas cidades. No Nordeste, são mais de $26 \%$ da população em áreas rurais, contra menos de $7 \%$ no Sudeste. ${ }^{12} \mathrm{O}$ baixo número de casos nas regiões Norte e Nordeste pode ser associado ao conhecimento tradicional da população das zonas rurais quanto às espécies de plantas e seu uso para diversas finalidades, como no caso de plantas medicinais, que por vezes é o único recurso terapêutico disponível em muitas comunidades e grupos étnicos. ${ }^{14,15} \mathrm{~A}$ urbanização, globalização e industrialização são processos que ocasionam alterações de valores e conceitos, contribuindo para que ocorram transformações naturais, o que pode resultar na perda de elementos e conhecimentos tradicionais importantes, que normalmente são transmitidos de geração em geração. ${ }^{15}$ Essa perda de conhecimentos tradicionais é refletida nos números das intoxicações por plantas tão desconformes entre zonas rurais e urbanas (Figura 3). Essas mesmas estatísticas mostram que os casos de intoxicação doméstica mais comuns ocorrem com

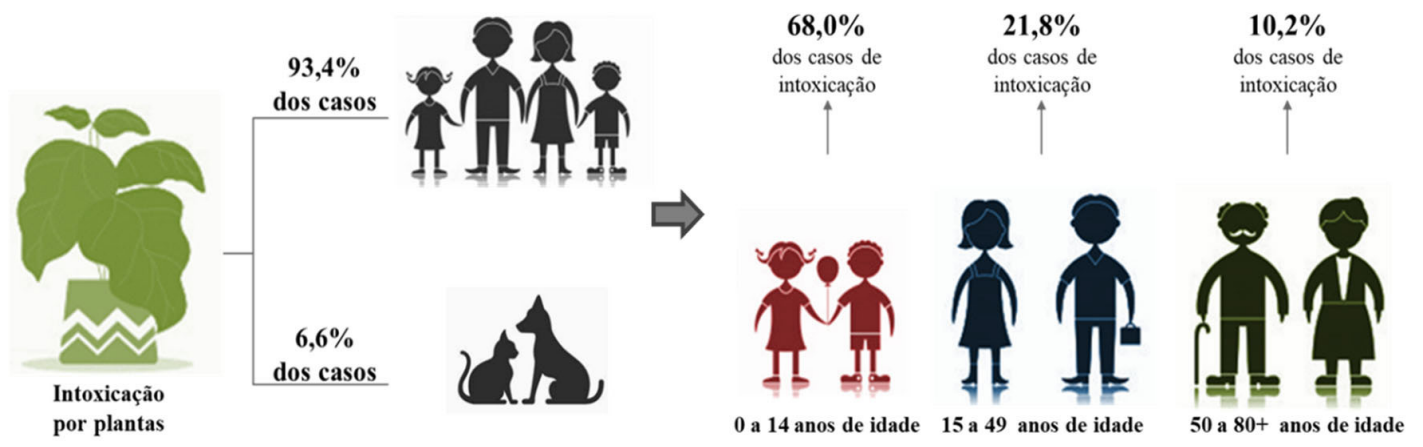

Figura 2. Faixas etárias dos casos de intoxicação por plantas ${ }^{9}$
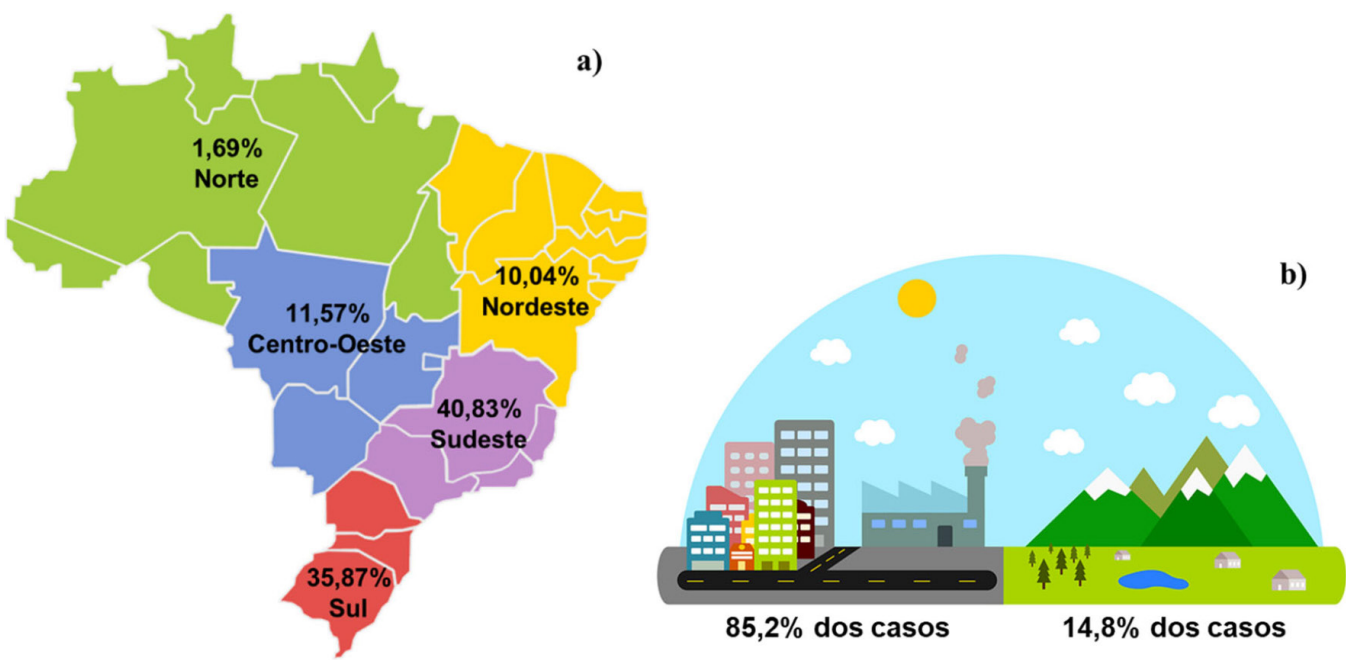

Figura 3. Casos de intoxicação por plantas ; a) por região brasileira; b) nas zonas urbana e rural 
cosméticos, alimentos e plantas, devido ao fácil acesso a esses componentes por crianças e animais domésticos (Figura 4). ${ }^{9}$

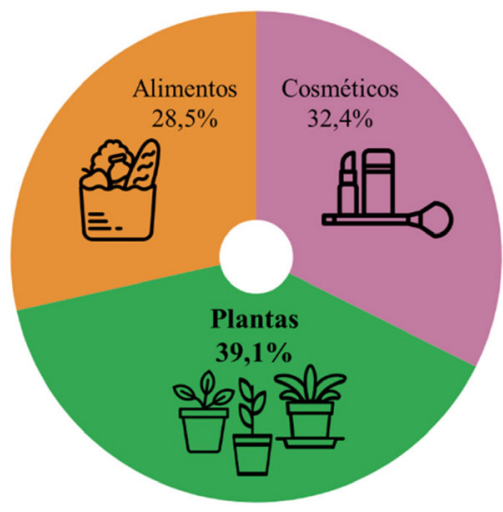

Figura 4. Causadores de intoxicações domésticas para crianças $^{9}$

Esse alto índice de intoxicações por plantas se deve ao fato de muitas espécies tóxicas serem comumente utilizadas como decorações em ambientes domésticos. No entanto, devido à falta de conhecimento sobre a toxicidade destas espécies, muitas vezes elas são colocadas em locais de fácil acesso para crianças e animais, que em consequência de sua curiosidade natural, acabam se acidentando. No Quadro 1

Quadro 1. Plantas tóxicas mais comumente empregadas como ornamentais no Brasil

\begin{tabular}{|c|c|c|}
\hline Nome Popular & Nome Científico & Família Botânica \\
\hline Rosa do deserto ${ }^{16}$ & Adenium obesum & Apocynaceae \\
\hline Antúrio $3,7,16$ & $\begin{array}{l}\text { Anthurium } \\
\text { andraeanum }\end{array}$ & Araceae \\
\hline Beladona $^{3,17}$ & Amaryllis belladonna & Amaryllidaceae \\
\hline $\begin{array}{l}\text { Comigo ninguém } \\
\text { pode }^{3,5,16}\end{array}$ & Dieffenbachia picta & Araceae \\
\hline Dedaleira $^{3}$ & Digitalis purpurea & Plantaginaceae \\
\hline Espirradeira $^{3,5,7}$ & Nerium oleander & Apocynaceae \\
\hline Espada de São Jorge $^{18}$ & Sansevieria trifasciata & Asparagaceae \\
\hline Urtiga $^{8}$ & Urtica dioica & Urticaceae \\
\hline Taioba $^{16}$ & $\begin{array}{c}\text { Xanthosoma } \\
\text { sagittifolium } \\
\text { Xanthosoma robustum }\end{array}$ & Araceae \\
\hline Copo de leite 3,5 & $\begin{array}{c}\text { Spathiphyllum willisii } \\
\text { Zantedeschia } \\
\text { aethiopica } \\
\text { Datura metel }\end{array}$ & $\begin{array}{c}\text { Araceae } \\
\text { Araceae } \\
\text { Solanaceae }\end{array}$ \\
\hline $\begin{array}{l}\text { Alamanda, dedal de } \\
\text { dama }^{5,7,8}\end{array}$ & Allamanda cathartica & Apocynaceae \\
\hline Vinca $^{16,18}$ & Catharanthus roseus & Apocynaceae \\
\hline $\begin{array}{l}\text { Chapéu de Napo- } \\
\text { leão }^{16,18}\end{array}$ & Thevetia peruviana & Apocynaceae \\
\hline Azevinho $^{19}$ & Ilex aquifolium & Aquifoliaceae \\
\hline Café de salão ${ }^{11}$ & $\begin{array}{c}\text { Aglaonema commu- } \\
\text { tatum }\end{array}$ & Araceae \\
\hline Cicuta venenosa $a^{20,21}$ & Conium maculatum & Apiaceae \\
\hline Jasmin manga $^{13}$ & Plumeria rubra & Apocynaceae \\
\hline Lírio da paz ${ }^{16,21}$ & Spathiphyllum wallisii & Araceae \\
\hline $\begin{array}{c}\text { Palmeira rabo de } \\
\text { peixe }^{18}\end{array}$ & Caryota mitis & Arecaceae \\
\hline Bombardeira $^{22}$ & Calotropis procera & Asclepidaceae \\
\hline
\end{tabular}

estão listadas as plantas ornamentais mais empregadas no Brasil e que possuem substâncias tóxicas. A tabela completa pode ser encontrada no Material Suplementar.

Chama a atenção no Quadro 1 a quantidade de espécies das famílias Araceae e Apocynaceae, espécies usualmente relacionadas à produção de látex vesicantes e urticantes. Várias dessas espécies tóxicas possuem outros usos além do ornamental. A Taioba é uma planta alimentícia com extenso consumo do tubérculo (batata) e também da folha cozida, apesar de ambos serem tóxicos. A Espirradeira possui diversos usos medicinais como a infusão das folhas para insuficiência cardíaca e para acelerar a maturação de abcessos, e diversos usos populares relacionados com sua toxicidade, como no tratamento da escabiose, como abortiva e também citotóxica e depressora do Sistema Nervoso Central. ${ }^{23} \mathrm{~A}$ Urtiga possui pelos contendo ácido fórmico com forte ação urticante, mas é uma planta da medicina tradicional mundialmente empregada por suas diversas propriedades, como diurético, hipotensivo e no tratamento da rinite. ${ }^{24}$ Considerada uma das plantas mais bonitas e perigosas entre as plantas medicinais, a Dedaleira tem glicosídeos de uso extenso no tratamento de doenças cardíacas, como arritmias. ${ }^{24}$ O Copo-de-leite, também conhecido como trombeteira, possui flores brancas de grande beleza com uso medicinal no controle da dispneia asmática e frutos semelhantes ao maxixe, especialmente mais perigosos às crianças. Usa-se compressas de suas folhas em inflamações e dores reumáticas. ${ }^{24-26}$ Uso semelhante na medicina popular é atribuído à Espada-de-São-Jorge, um exemplo de planta ornamental amplamente utilizada no Brasil que possui forte emprego religioso e em ritos afro-brasileiros para proteger ambientes, em defumadores, banhos de descarrego, para afastar as energias ruins e os invejosos. ${ }^{26}$ Usos rituais e místicos semelhantes são atribuídos à Comigo-Ninguém-Pode. ${ }^{25-27}$

\section{Principais agentes tóxicos em plantas ornamentais}

Entre as substâncias naturais, os metabólitos primários, aqueles essenciais à nutrição, crescimento e reprodução das espécies, estão presentes de forma bastante homogênea em todas as plantas. Já o outro conjunto de substâncias, ora denominado de secundárias e atualmente denominado metabólitos especializados, são substâncias menos comuns, relacionadas a efeitos de proteção e comunicação entre as espécies. São muitas vezes específicas de algumas famílias botânicas, podendo ser empregadas como marcadores taxonômicos e associadas a efeitos biológicos diversos, como ações medicinais, curativas e também tóxicas. A diferença entre o efeito medicinal ou tóxico é muitas vezes a dose. As substâncias ativas das plantas são empregadas com fins terapêuticos em formulações e posologias bastante específicas. Assim, a quantidade absorvida será a mínima possível para gerar o efeito biológico, face aos efeitos tóxicos possíveis. $^{28}$

O principal relato é do ácido oxálico e seus sais, principalmente o oxalato de cálcio. Além deles, diversas substâncias das classes dos alcaloides e terpenos, e em especial substâncias glicosiladas como as saponinas e os glicosídeos cardiotóxicos e cianogênicos.

\section{Oxalato de cálcio}

Oxalato de cálcio é uma das substâncias tóxicas mais frequentemente encontradas em organismos vegetais. Cristais de oxalato de cálcio em plantas são conhecidos por ocorrerem na maioria das famílias vegetais, podendo ser observados em todos os tecidos e órgãos da planta, em depósitos intra ou extracelulares. ${ }^{29,30} \mathrm{O}$ oxalato de cálcio (Figura 5) é um produto cujos íons de $\mathrm{Ca}^{2+}$ são derivados do próprio meio ambiente ${ }^{31} \mathrm{e}$ a formação de seus cristais em organismos 
vegetais ocorre por meio de uma reação com o ácido oxálico que é biologicamente sintetizado pela planta. ${ }^{32}$

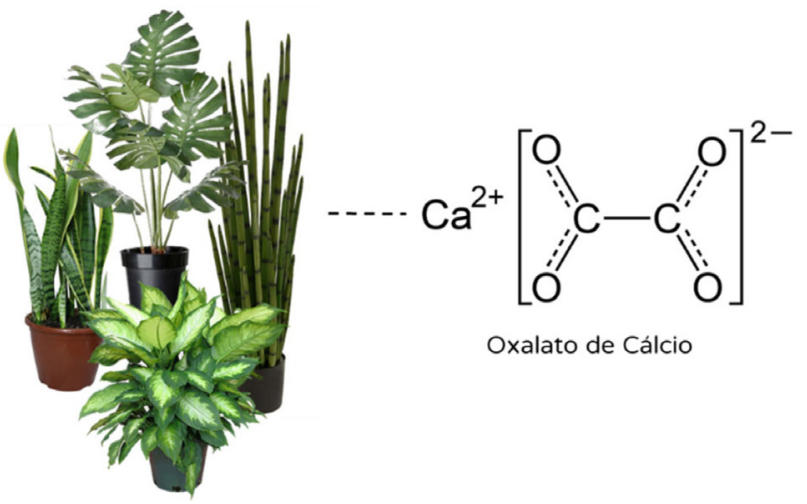

Figura 5. Presença de oxalato de cálcio em algumas espécies

A distribuição do oxalato de cálcio em diversos grupos de organismos mostra que possui uma função de biomineralização comum e importante para as plantas. Essa função corresponde ao processo pelo qual organismos vivos formam cristais inorgânicos ou agregados cristalinos. ${ }^{33} \mathrm{~A}$ deposição destes cristais pode ocorrer em vacúolos das células ou associado às suas paredes. Estas células são normalmente especializadas em sua formação e são chamadas de idioblastos, conhecidos como células injetoras devido à forma como os cristais são liberados. ${ }^{29,30}$ Os formatos dos cristais de oxalato de cálcio variam e são normalmente descritos como prismas, ráfides, estiloides, drusas ou areia cristalina (Figura 6). ${ }^{34}$

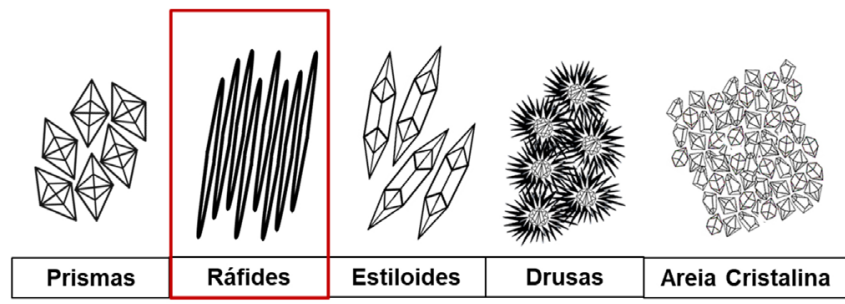

Figura 6. Formato dos cristais de oxalato de cálcio encontrados em diversas plantas

A presença de cristais de oxalato de cálcio denominados ráfides (que possuem formato de agulha) é o principal causador das intoxicações e são comumente encontrados em plantas da família Araceae. As ráfides são perfurantes e quando em contato com a pele e/ou mucosas podem causar hipocalcemia, conjuntivite, dermatite, distúrbios gastrointestinais (Figura 7) e em casos mais sérios de asfixia, podem levar a óbito devido à obstrução das vias áreas. ${ }^{35}$ Além disso, plantas que possuem oxalato de cálcio, quando ingeridas, podem também atuar como antinutrientes ou como uma toxina e colaborar com a formação e acúmulo de pedras de oxalato de cálcio nos rins. ${ }^{30,36}$

Quanto à morfologia dos cristais produzidos, pode ser formado

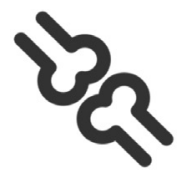

$\downarrow$

Hipocalcemia

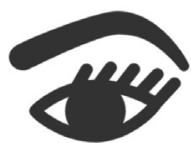

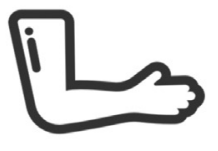

Dermatite

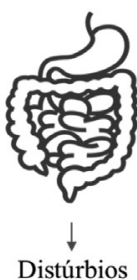

Distúrbios
Figura 7. Principais sintomas causados pela intoxicação por oxalato de cálcio um único tipo por toda a planta, múltiplos tipos sendo um específico para cada órgão e até mesmo múltiplos tipos no mesmo órgão, mas em regiões e tecidos diferentes. Mesmo com essas distribuições distintas (Figura 8), a morfologia do cristal e sua distribuição são constantes entre as espécies, podendo ser usadas como um caráter taxonômico e indicar uma solida regulação genética de deposição de cristal. ${ }^{29,30} \mathrm{~A}$ ampla variação na distribuição dos cristais pelos órgãos, tecidos, células e localidades subcelulares dentre as espécies sugere origens múltiplas e independentes para a formação do oxalato de cálcio e as funções atribuídas a este composto. Baseado na variedade dos tamanhos e formatos dos cristais formados, assim como em sua prevalência e distribuição espacial, existem inúmeras hipóteses a respeito da função desses cristais na planta, dentre as quais se destacam a regulação de cálcio, a proteção externa contra animais e desintoxicação de metais pesados, podendo também atuar no balanço iônico, na rigidez da estrutura, no suporte de tecidos e até mesmo na coleta de luz. ${ }^{29,30}$

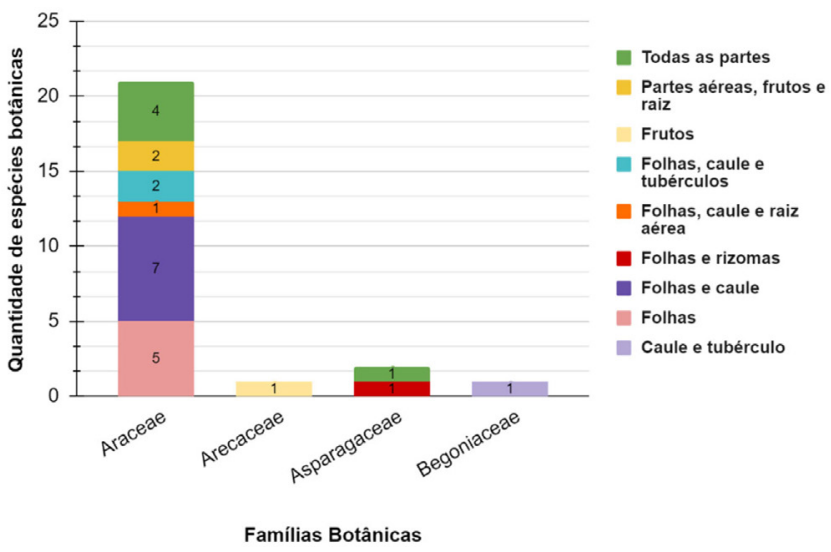

Figura 8. Distribuição distinta do oxalato de cálcio por diferentes partes das plantas

Dentre as principais espécies utilizadas como ornamentais e nas quais se é notável a presença de oxalato de cálcio estão as plantas do Quadro 2. Pode-se destacar entre essas a taioba, planta alimentícia que apresenta oxalato de cálcio tanto nas folhas quanto nos tubérculos. ${ }^{37}$

Diversos estudos fisiológicos e biológicos têm mostrado que o oxalato de cálcio funciona como parte de um mecanismo para a regulação de cálcio nos órgãos e tecidos da planta. Assim, a quantidade e o tamanho dos cristais de oxalato de cálcio encontrados são diretamente ligados à concentração de cálcio no organismo vegetal. ${ }^{36}$ Essa regulação de cálcio normalmente é necessária em plantas que crescem em ambientes onde há abundância de cálcio solúvel e as raízes não conseguem controlar sua entrada na planta. Logo, quando a água é evaporada da superfície, o cálcio dissolvido é deixado pra trás, muitas vezes acumulando-se em altos níveis. Como o cálcio faz parte de diversos processos bioquímicos e celulares, o controle de sua concentração dentro da célula vegetal deve ser cuidadoso, sendo esse o motivo para que ocorra a precipitação desse excesso de cálcio em oxalato de cálcio, que é fisiologicamente e osmoticamente inativo. ${ }^{30,36}$

Quanto ao papel dos cristais de oxalato de cálcio em relação à defesa e à proteção da planta, parâmetros morfológicos, espaciais e temporais são levados em consideração. A mecânica de ação dos cristais quanto a essa função pode ser passiva, assim como pode ser extremamente ativa, como nos casos de plantas que apresentam pelos urticantes que ao entrar em contato com a derme de animais e seres humanos, causam sensação de queimação. Esses pelos consistem em uma célula pungente alongada, contendo cristais de oxalato de cálcio em formato de ráfides, que quando entra em contato com alguma superfície, tem sua ponta rompida, permitindo assim que os ráfides 
Quadro 2. Espécies ornamentais mais conhecidas, que possuem oxalato de cálcio

\begin{tabular}{|c|c|c|}
\hline Nome Popular & Nome Científico & Família Botânica \\
\hline Café de salão ${ }^{11}$ & $\begin{array}{c}\text { Aglaonema commu- } \\
\text { tatum }\end{array}$ & Araceae \\
\hline $\begin{array}{l}\text { Alocasia amazôni- } \\
\mathrm{ca}^{16,18}\end{array}$ & Alocasia amazonica & Araceae \\
\hline $\begin{array}{c}\text { Orelha de elefante } \\
\text { gigante }^{16,18}\end{array}$ & Alocasia macrorrhiza & Araceae \\
\hline Jack $^{6,38}$ & Arisaema triphyllum & Araceae \\
\hline Adão e Eva ${ }^{20}$ & Arum maculatum & Araceae \\
\hline Arum $^{20}$ & Arum palaestinum & Araceae \\
\hline Antúrio ${ }^{7,16,20}$ & $\begin{array}{l}\text { Anthurium an- } \\
\text { draeanum }\end{array}$ & Araceae \\
\hline Begônia tuberosa ${ }^{6}$ & Begonia tuberhybrida & Begoniaceae \\
\hline Calla $^{39}$ & Calla palustris & Araceae \\
\hline $\begin{array}{l}\text { Palmeira rabo de } \\
\text { peixe }^{18}\end{array}$ & Caryota mitis & Arecaceae \\
\hline Taro $^{40}$ & Colocasia esculentum & Araceae \\
\hline Tinhorão, tajá $a^{5,716}$ & Caladium bicolor & Araceae \\
\hline Taioba brava ${ }^{41}$ & Colocasia antiquora & Araceae \\
\hline $\begin{array}{l}\text { Comigo ninguém } \\
\text { pode }^{3,5,7,16}\end{array}$ & Dieffenbachia picta & Araceae \\
\hline Jibóia $^{6}$ & Epipremnum aureum & Araceae \\
\hline Costela de Adão $0^{42}$ & Monstera deliciosa & Araceae \\
\hline Banana de macaco ${ }^{20}$ & $\begin{array}{l}\text { Philodendron bipinna- } \\
\text { tifidum }\end{array}$ & Araceae \\
\hline Filodendro Brasil ${ }^{20}$ & $\begin{array}{l}\text { Philodendron oxycar- } \\
\text { dium }\end{array}$ & Araceae \\
\hline Pistia $^{43}$ & Pistia stratiotes & Araceae \\
\hline Lança de São Jorge $^{18}$ & Sansevieria cylindrica & Asparagaceae \\
\hline Espada de São Jorge ${ }^{18}$ & Sansevieria trifasciata & Asparagaceae \\
\hline Lírio da paz ${ }^{16,21}$ & Spathiphyllum wallisii & Araceae \\
\hline Taioba $^{16}$ & $\begin{array}{l}\text { Xanthosoma } \\
\text { sagittifolium }\end{array}$ & Araceae \\
\hline Copo de leite ${ }^{5,20,21}$ & $\begin{array}{c}\text { Zantedeschia } \\
\text { aethiopica }\end{array}$ & Araceae \\
\hline Arum dourado ${ }^{7}$ & $\begin{array}{l}\text { Zantedeschia ellio- } \\
\text { ttana }\end{array}$ & Araceae \\
\hline
\end{tabular}

perfurem a derme do organismo que a tocou, fazendo com que a seiva da planta seja canalizada ao longo da fenda do cristal até o local do ferimento, podendo causar irritação dérmica. ${ }^{30,36}$

Além das funções já citadas, diversos estudos também mostram que um papel possível para o oxalato de cálcio é permitir que a planta tolere diversos metais pesados. ${ }^{30,36}$ Algumas plantas utilizam o oxalato para se desintoxicar desses metais (como cádmio, chumbo, alumínio, estrôncio), quando estes estão presentes no solo. Dentre os metais pesados comumente encontrados em solos, o alumínio é o maior causador de problemas quanto ao desenvolvimento das plantas, pois mínimas concentrações deste metal podem inibir o crescimento das raízes e assim limitar a obtenção de nutrientes e água pelo organismo vegetal..$^{30,36}$

\section{Alcaloides}

Desde os tempos de Hipócrates, extratos de plantas são conhecidos por servirem como remédio para várias doenças. Mais tarde, muitos dos respectivos princípios ativos desses extratos vegetais foram identificados como alcaloides. ${ }^{44}$ Alcaloides são compostos orgânicos básicos que possuem nitrogênio em sua cadeia, normalmente em uma estrutura heterocíclica ou aromática. Muitas plantas com funções medicinais possuem seus efeitos graças à presença destas substâncias, portanto tem sido crescente sua exploração na pesquisa, para que se possa entender o funcionamento dos mecanismos por onde exercem seus efeitos, assim como determinar suas estruturas e as sínteses que elas apresentam. Acredita-se que a função dos alcaloides no metabolismo de uma planta seja unicamente de proteção, atuando como veneno ou repelente contra predadores, parasitas e competidores. ${ }^{45}$ Dentre as plantas ornamentais tóxicas que possuem alcaloides, as mais conhecidas são mostradas no Quadro 3 .

Quadro 3. Espécies ornamentais mais conhecidas, que possuem alcaloides tóxicos

\begin{tabular}{|ccc|}
\hline Nome Popular & Nome Científico & Família Botânica \\
\hline Capacete de Júpiter $^{20,46}$ & Aconitum napellus & Rununculaceae \\
\hline Beladona $^{3,47}$ & Atropa belladonna & Amaryllidaceae \\
\hline Lírio trombeta $^{48,49}$ & $\begin{array}{c}\text { Brugmansia } \\
\text { suaveolens }\end{array}$ & Solanaceae \\
\hline Cróton $^{8,18}$ & Codiaeum variegatum $^{48}$ & Euphorbiaceae \\
\hline Estramônio $^{47}$ & Datura stramonium & Solanaceae \\
\hline Açucena $^{16}$ & $\begin{array}{c}\text { Hippeastrum } \\
\text { hybridum }\end{array}$ & Amaryllidaceae \\
\hline Ipoméia $^{3}$ & Ipomoea coerulea & Convolvulaceae \\
\hline Charuto do rei $^{8,50}$ & Nicotiana glauca & Solanaceae \\
\hline Papoula $^{51}$ & Papaver somniferum & Papaveraceae \\
\hline Violeta $^{3}$ & Viola odorata & Violaceae \\
\hline Chuva de ouro $^{44,46}$ & $\begin{array}{c}\text { Laburnum anagyroi- } \\
\text { des }\end{array}$ & Fabaceae \\
\hline Feijão coral $^{21}$ & Sophora secundiflora & Fabaceae \\
\hline Maravilha $^{11,52}$ & Mirabilis jalapa & Nyctagenaceae \\
\hline Vinca $^{16,18}$ & Catharanthus roseus & Apocynaceae \\
\hline Clivia $^{11}$ & Clivia miniata & Amaryllidaceae \\
\hline Algodão do brejo $^{2}$ & Ipomoea fistulosa & Convolvulaceae \\
\hline & &
\end{tabular}

Milhares de alcaloides são conhecidos, porém poucos são tóxicos. Os alcaloides mais tóxicos caracterizam-se por ter sabor amargo, fator importante para prevenir a ingestão da planta. ${ }^{53}$ Dentre os alcaloides tóxicos encontrados em plantas, os chamados "beladonados" são os mais conhecidos e consistem na escopolamina, 1-hiosciamina e atropina (mistura racêmica de d-hiosciamina e 1-hiosciamina) (Figura 9). Estas substâncias são alcaloides tropânicos encontrados em várias plantas, como a beladona (Atropa belladonna), por isso o nome associado a eles.

Seus efeitos tóxicos se devem ao fato desses compostos serem anticolinérgicos, que atuam como antagonistas da acetilcolina. Esses alcaloides inibem os receptores muscarínicos, que são responsáveis por captar sinais extracelulares e ativam vias de transdução de sinal no interior da célula, agindo no sistema parassimpático. Antagonistas muscarínicos possuem um efeito estimulatório sobre a atividade locomotora, mediado pelo aumento na liberação de acetilcolina. ${ }^{48}$ Plantas contendo substâncias anticolinérgicas vêm sendo utilizadas há muitos séculos em medicamentos fitoterápicos, em cerimônias religiosas e também como venenos. Como a acetilcolina é uma molécula mensageira essencial para a ativação muscular, para as glândulas que secretam fluidos corporais e para muitas funções cerebrais, esses alcaloides são responsáveis por interferir em todos esses processos. ${ }^{54}$ 


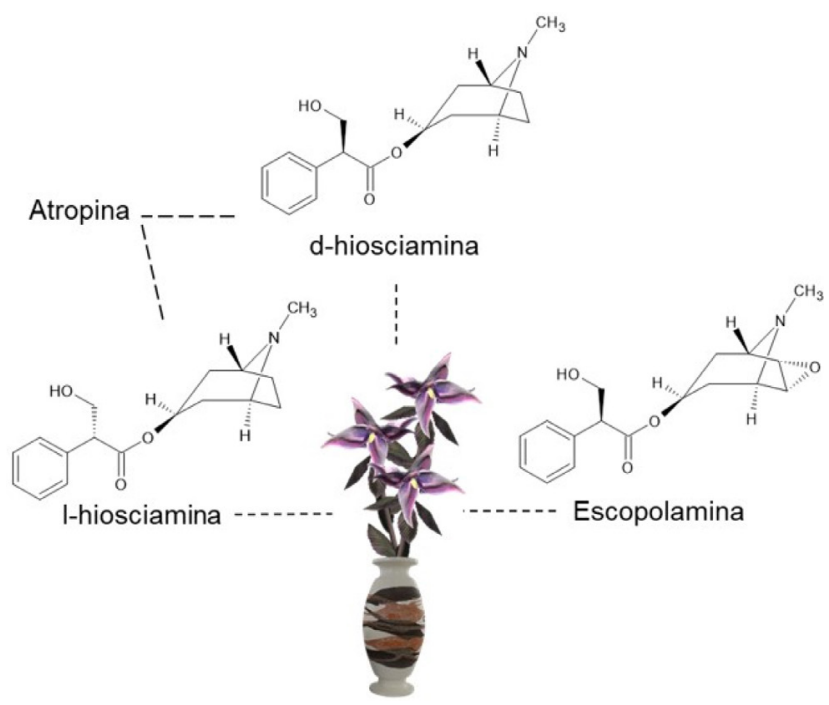

Figura 9. Estruturas dos principais alcaloides tropânicos

\section{Glicosídeos: cianogênicos, cardiotóxicos e saponinas}

Uma vasta gama de glicosídeos tóxicos ocorre em plantas vasculares e os mais abundantes são glicosídeos cardiotóxicos, glicosídeos cianogênicos e as saponinas. Dentre as funções destes compostos, as principais são a atração de polinizadores ou dispersores de sementes e a repulsão ou inibição de herbívoros e microrganismos. Concentrações de glicosídeos tóxicos em plantas podem ser significativamente afetadas por estresse fisiológico no ambiente em que se encontram, como deficiência de água ou de nutrientes. Outros fatores que podem afetar os níveis de glicosídeos são o estágio de crescimento, a acumulação em tecidos específicos da planta, a localização geográfica e topográfica da planta e os efeitos sazonais do clima e do solo. ${ }^{55}$ Além dos principais glicosídeos tóxicos (cardiotóxicos, cianogênicos e saponinas) também podem ser encontrados glicosídeos antraquinônicos, terpenoides, indoides, esteroides e cumarínicos.

\section{Glicosídeos cianogênicos}

Glicosídeos cianogênicos, quando enzimaticamente hidrolisados, formam ácido cianídrico em um processo definido como cianogênese. O ácido cianídrico é extremamente tóxico para inúmeros organismos devido à sua habilidade de se ligar com metais que são grupos funcionais de diversas enzimas, inibindo processos como redução de oxigênio na cadeia respiratória e transporte de íons na fotossíntese e em atividades enzimáticas. Existem fortes evidências de que a cianogênese é um dos mecanismos utilizados pela planta como defesa contra predadores. ${ }^{56,57}$ Dentre as principais plantas que possuem glicosídeos cianogênicos (Quadro 4) estão:

Quadro 4. Espécies ornamentais mais conhecidas, que possuem glicosídeos cianogênicos

\begin{tabular}{|c|c|c|}
\hline Nome Popular & Nome Científico & Família Botânica \\
\hline Adão e Eva $^{20}$ & Arum maculatum & Araceae \\
\hline Arum $^{20}$ & Arum palaestinum & Araceae \\
\hline Bambu $^{58}$ & Bambusa vulgaris & Poaceae \\
\hline Hortência $^{59}$ & $\begin{array}{c}\text { Hydrangea } \\
\text { macrophylla }\end{array}$ & Saxifragaceae \\
\hline Teixo $^{60}$ & Taxus baccata & Taxaceae \\
\hline
\end{tabular}

Em plantas, a cianogênese ou a liberação de $\mathrm{HCN}$ é associada com a perturbação das células seguido de autólise conforme os glicosídeos são expostos às enzimas endógenas das plantas. As agliconas resultantes são cianoidrinas instáveis. Em pH fisiológico, elas sofrem uma rápida dissociação para produzir $\mathrm{HCN}$ e até mesmo um aldeído ou cetona. A dissociação é uma reação dependente de $\mathrm{pH}$ com altos níveis de formação de $\mathrm{HCN}$ ocorrendo a um $\mathrm{pH}$ maior que 6 e baixos níveis de formação em pH entre 5 e 6 . A toxicidade do HCN no organismo é devido ao bloqueio da respiração celular aeróbica. $\mathrm{O}$ efeito tóxico é majoritariamente atribuído à inibição da citocromo oxidase, mas outros processos metabólicos também podem ser afetados. ${ }^{55}$

\section{Glicosídeos cardiotóxicos}

Glicosídeos cardiotóxicos são normalmente compostos de origem vegetal e consistem de uma aglicona combinada com uma molécula de açúcar. As agliconas de glicosídeos cardiotóxicos podem ser divididas em dois grupos distintos: cardenolídeos e bufadienolídeos. Estruturalmente, como mostra a Figura 10, na posição do carbono 17, cardenolídeos tem uma lactona cíclica insaturada de 5 membros enquanto bufadienolídeos possuem uma lactona cíclica de 6 membros duplamente insaturada. Em ambos, o grupo R indica a glicosilação, um açúcar na posição 3 , ligado ao oxigênio. ${ }^{61}$

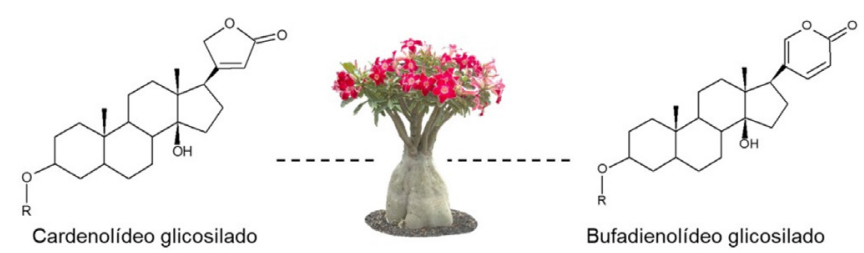

Figura 10. Estruturas dos dois grupos distintos das agliconas de glicosídeos cardiotônicos

Glicosídeos cardiotóxicos atuam na inibição da membrana celular $\mathrm{Na}^{+} / \mathrm{K}^{+}$ATPase (Figura 11), que é bomba responsável pelo transporte ativo e contínuo de íons sódio e potássio e que está diretamente ligada aos processos de contração muscular e condução dos impulsos nervosos. A inibição dessa bomba resulta no esgotamento do potássio intracelular e, portanto, aumenta a quantidade de sódio, o que leva à acumulação elevada de cálcio no sistema. ${ }^{62,63}$

A inibição por cardenolídeos afeta as concentrações eletrolíticas intracelulares, resultando em contrações do miocárdio muito potentes. São substâncias terapêuticas para humanos, em doses medicinais, mas também são tóxicas quando consumidas nas concentrações naturais encontradas nas plantas. Todos os glicosídeos cardiotóxicos devem ser considerados como altamente tóxicos. ${ }^{55}$ Dentre as espécies de plantas que possuem glicosídeos cardiotóxicos, as principais estão listadas no Quadro 5:

\section{Saponinas}

Saponinas são um amplo grupo de metabólitos especializados que ocorre em quantidades significativas em diversas espécies de plantas. As saponinas são glicosídeos conjugados de triterpenos ou de esteroides. Na Figura 12, dois exemplos de modelos de saponinas são apresentados, com esqueletos esteroidal e triterpênico e o grupo $\mathrm{R}$ relativo à posição mais comum do açúcar (semelhante aos glicosídeos cardiotônicos da Figura 10). Seu nome deriva do fato de suas propriedades serem semelhantes às do sabão (soap em inglês), como a de formar espumas estáveis quando agitadas e diluídas em soluções aquosas ${ }^{55}$ A concentração de saponinas nas plantas é variável e o clima local, mudanças sazonais, condições externas como luz, temperatura, umidade e fertilidade do solo, assim como técnicas de cultivo, afetam ambas a quantidade e a composição qualitativa das saponinas. ${ }^{64}$

Apesar de sua ampla distribuição, apenas um pequeno número de espécies vegetais contém saponinas que são tóxicas para mamíferos, 


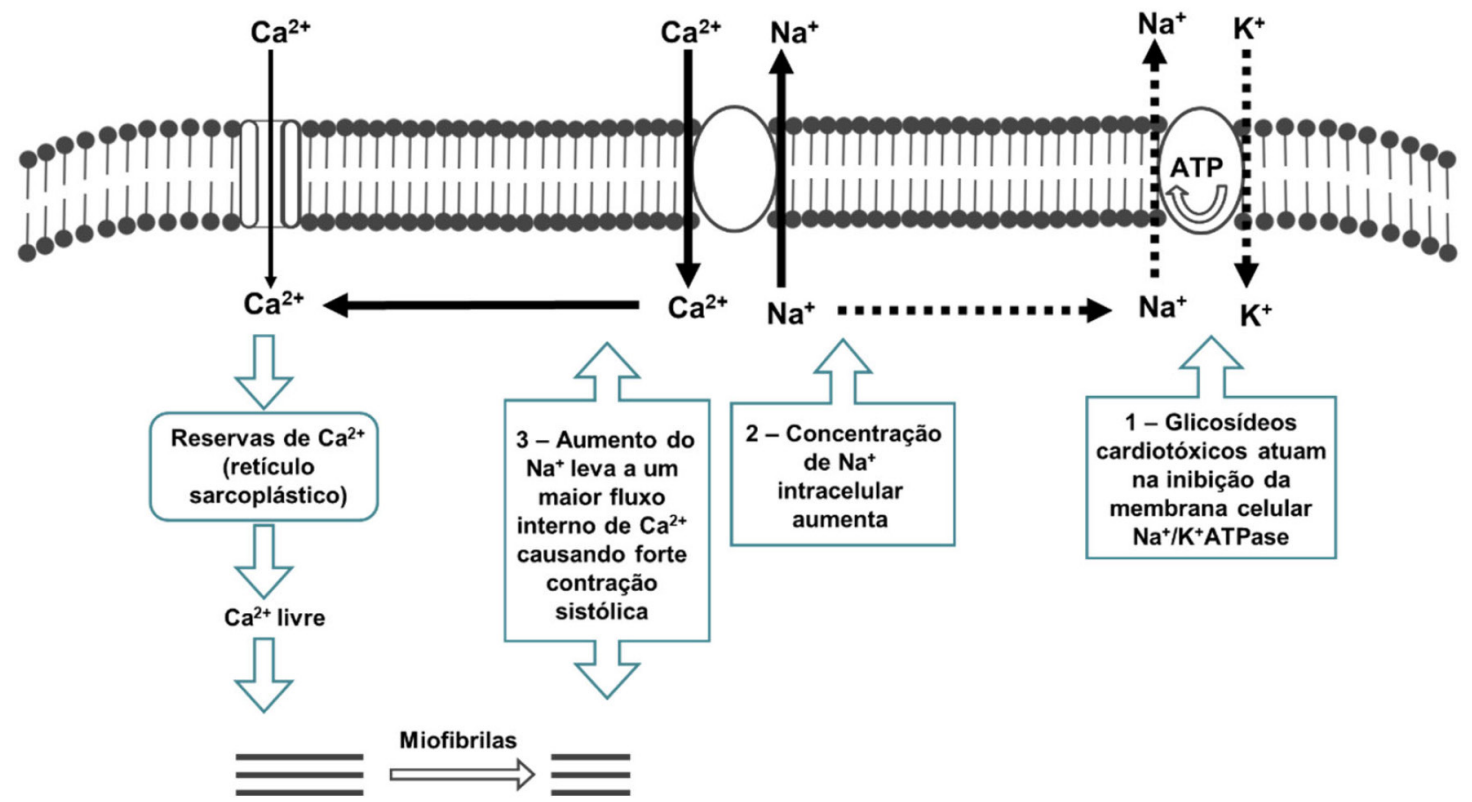

Figura 11. Mecanismo de atuação de glicosídeos cardiotóxicos na inibição da membrana celular $\mathrm{Na}^{+} / \mathrm{K}^{+}$ATPase

Quadro 5. Espécies ornamentais mais conhecidas, que possuem glicosídeos cardiotóxicos

\begin{tabular}{|c|c|c|}
\hline Nome Popular & Nome Científico & Família Botânica \\
\hline Rosa do deserto $^{16}$ & Adenium obesum & Apocynaceae \\
\hline Adônis da primavera $^{20}$ & Adonis vernalis & Ranunculaceae \\
\hline Aspargo $^{46}$ & Asparagus officinalis & Asparagaceae \\
\hline Dedaleira $^{20,21}$ & Digitalis purpurea & Plantaginaceae \\
\hline $\begin{array}{c}\text { Chapéu de } \\
\text { Napoleão }\end{array}$,16,18 & Thevetia peruviana & Apocynaceae \\
\hline
\end{tabular}<smiles>CC(C)CCCC(C)[C@H]1CCC2C3CC=C4C[C@@H](O)CC[C@]4(C)[C@H]3CC[C@]21C</smiles>

Esqueleto esteroidal

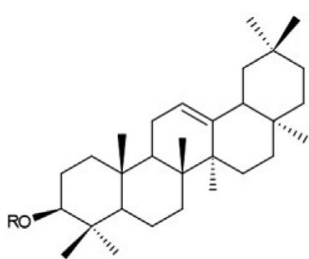

Esqueleto triterpenoide pentacíclico

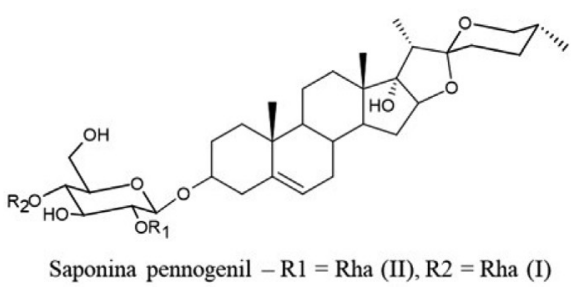

Figura 12. Estruturas das saponinas derivadas de esteroides e triterpenos, respectivamente

as mais conhecidas estão listadas no Quadro 6. Um exemplo de saponina presente em uma das espécies desse quadro é apresentado na Figura 12, uma saponina do tipo pennogenil (SP), de Paris quadrifolia.$^{65}$ Essa toxicidade é atribuída à dificuldade de absorção desta substância pelo trato gastrointestinal. O efeito tóxico das saponinas é geralmente iniciado pela interação com as membranas mucosas, causando alterações de permeabilidade ou perda de enzimas ligadas à membrana. A destruição da aderência das membranas celulares da mucosa resulta em lesões intestinais e gastroenterite grave. Nessas condições, as saponinas podem ser absorvidas pelo trato gastrointestinal e produzir efeitos sistêmicos, como danos ao fígado, insuficiência respiratória, convulsões violentas e coma. A capacidade das saponinas de romper as membranas celulares aumenta sua atividade quando administradas por via intravenosa. ${ }^{55}$

Quadro 6. Espécies ornamentais mais conhecidas, que possuem saponinas

\begin{tabular}{|c|c|c|}
\hline Nome Popular & Nome Científico & Família Botânica \\
\hline Ciclame da Pérsia $^{20}$ & Cyclamen persicum & Myrsinaceae \\
\hline Pingo de ouro & Duranta repens & Verbenaceae \\
\hline Erva Paris $^{20}$ & Paris quadrifolia & Melanthiaceae \\
\hline Sapatinho do diabo $^{16}$ & $\begin{array}{c}\text { Pedilanthus } \\
\text { tithymaloides }\end{array}$ & Euphorbiaceae \\
\hline Primula $^{20}$ & Primula obconica & Primulaceae \\
\hline
\end{tabular}

\section{Outros metabólitos tóxicos}

Além de alcaloides, cristais de oxalato de cálcio, terpenos e glicosídeos, outros metabólitos secundários tóxicos também são encontrados em diversas espécies de organismos vegetais, porém com menor frequência. Alguns deles são: aminoácidos neutoróxicos, andromedotoxinas, quinonas, compostos de poliacetileno, compostos fenólicos, ácidos orgânicos, taninos, ésteres, felandreno, catecois, iridoides, cumarinas, flavononas, lactonas, lantadenos, lignanas, priminas, éteres, flavonoides e toxalbuminas. Tais metabólitos possuem propriedades medicinais, mas dependendo do modo e da quantidade de exposição podem ser tóxicos e acarretar diversos sintomas como dermatites de contato e distúrbios gastrointestinais.

\section{CONCLUSÕES}

Uma ampla variedade de plantas ornamentais presentes nos lares dos brasileiros apresenta efeitos tóxicos, especialmente pela presença de oxalato de cálcio, mas também de alcaloides, saponinas e glicosídeos. Reconhecer seus efeitos e causas é essencial para mantêlos distantes das possibilidades de causarem intoxicação. 


\section{MATERIAL SUPLEMENTAR}

Mais informações sobre as plantas ornamentais, toxicidade e sintomatologia podem ser encontradas em http://quimicanova.sbq. org.br em formato PDF, com acesso livre.

\section{AGRADECIMENTOS}

Os autores agradecem ao CNPq e à FAPERJ pelas bolsas concedidas para a realização do projeto.

\section{REFERÊNCIAS}

1. Sá, M. R.; Revista Brasileira de História da Ciência 2012, 5 (supl), 12.

2. Hoehne, F. C.; Plantas e substâncias vegetais tóxicas e medicinais, Departamento de Botânica do Estado, São Paulo, 1939.

3. Mircea, C.; Draghia, L.; Bulletin UASVM Horticulture 2014, 71, 180.

4. Vasconcelos, J.; Vieira, J. G. de P.; Vieira, E. P. de P.; Rev. Cient. UFPA 2009, 7, 1 .

5. da Silva, P. H.; Oliveira, Y. R.; Silva, A. P. de J.; Barros, H. N. de B.; Meireles, V. de J. S.; de Barros, H. N.; de Abreu, M. C.; Rev. Intertox Toxicol. Risco Ambient. Soc. 2015, 8, 19.

6. Poppenga, R. H.; Mol. Clin. Environ. Toxicol. 2010, 2, 123.

7. Martins, T. D.; Geron, V. L. M. G.; Revista Científica Da Faculdade De Educação E Meio Ambiente 2014, 79.

8. Campos, S. C.; Silva, C. G.; Campana, P. R. V.; Almeida, V. L.; Rev. Bras. Plantas Med. 2016, 18, 373.

9. https://sinitox.icict.fiocruz.br/dados-nacionais, acessado em Março 2021.

10. Alves, R. B. da S.; de Lima, F. A.; Coutinho, M. de S.; de Meneses, A. B.; de Lima, E. L. M.; Meira, A. M. B.; de Araújo, C. R. F.; Mariz, S. R.; Revista Ciência em Extensão 2016, 12, 79.

11. Cuadra, V. P.; Cambi, V.; Rueda, M. de los Á.; Calfuán, M.; Ethnobotany Research and Applications 2012, 10, 77.

12. https://www.ibge.gov.br/estatisticas/sociais/habitacao, acessado em Março 2021.

13. Medeiros, L. F. S.; Pereira, M.; Nucleus 2008, 5, 209.

14. Rodrigues Silva, L. R.; Carolina de Abreu, M.; Pinheiro Ferreira, P. M.; Landim Pacheco, A. C.; Felício Calou, I. B.; Santos Cerqueira, G.; Revinter 2015, 7.

15. Hoeffel, J. L. de M.; Gonçalves, N. de M.; Fadini, A. A. B.; Seixas, S. R. da C.; Vitas 2011, $1,1$.

16. de Souza, R. dos S.; Biodiversidade 2019, 2, 79.

17. Martin, S. F.; Alkaloids Chem. Pharmacol. 1987, 30, 251.

18. Costa Silva, L.; Revista da Sociedade Brasileira de Arborização Urbana 2019, 4, 69.

19. Anadón, A.; Martínez-Larrañaga, M. R.; Ares, I.; Martínez, M. A.; Veterinary Toxicology: Basic and Clinical Principles 2018, 891.

20. Mircea, C.; Draguia, L.; Bull. Hortic. 2014, 71, 180.

21. Parker, D.; N. Z. Med. J. 2012, 125, 87.

22. Waikar, S.; Srivastava, V. K.; Med. J. Armed Forces India 2015, 71, 92.

23. Simões, C. M. O. Farmacognosia, da planta ao medicamento, $3^{\text {a }}$ ed., Editora da Universidade UFPR: Curitiba, 2001.

24. Lorenzi, H.; Matos, F. J. A.; Plantas Medicinais no Brasil, $1^{\text {a }}$ ed., Instituto Plantarum: Nova Odessa, 2008.

25. Neto, G. G.; Carniello, M. A.; Quintais Mato-Grossenses, $1^{\text {a }}$ ed., Unemat: Cáceres, 2008.

26. Franco, I. J.; Fontana, V. L.; Ervas e Plantas - A Medicina do Simples, $10^{\mathrm{a}}$ ed., Edelbra: Porto Alegre, 2003.

27. Farelli, M. H.; Plantas que Curam e Cortam Feitiços, $1^{\text {a }}$ ed., Pallas: Rio de Janeiro, 2002.
28. Veiga, V. F.; Pinto, A. C.; Maciel, M. A. M.; Quim. Nova 2005, 28, 519.

29. Franceschi, V. R.; Horner, H. T.; Bot. Rev. 1980, 46, 361.

30. Franceschi, V. R.; Nakata, P. A.; Annu. Rev. Plant Biol. 2005, 56, 41.

31. de Oliveira, R. R.; Pasin, L. A. A. P.; Revista de Ciências Ambientais 2017, 11, 41 .

32. Ciler, M.; Acta Biol. Cracov., Ser. Bot. 2009, 51, 105.

33. Gonzalez, J. A. Z.; Costa, M. D.; Silva, I. R.; Neves, J. C. L.; Barros, N. F. de; Borges, A. C.; Rev. Bras. Ciênc. Solo 2009, 33, 555

34. Doaigey, A. R.; Am. J. Bot. 1991, 78, 1608.

35. Saito, S. R. M.; Lima, V. F. G. A. P.; Rev. Saúde 2009, 3, 25.

36. Nakata, P. A.; Plant Sci. 2003, 164, 901.

37. Ramos, A. S.; Verçosa, R. M.; Teixeira, S. M. L.; Teixeira-Costa, B. E.; Cienc. Tec. Alim. 2020, 40, 705.

38. Jadhav, D. R.; Gugloth, R.; Indian J. Care Med. 2019, 23, 242.

39. Hsueh, K. F.; Lin, P. Y.; Lee, S. M.; Hsieh, C. F.; J. Chinese Med. Assoc. 2004, 67, 93.

40. Libert, B.; Franceschi, V. R.; J. Agric. Food Chem. 1987, 35, 926.

41. Lucena, G. L.; Silva, A. G.; Honório, L. M. C.; Santos, V. D.; Sci. Plena 2012, 8,1 .

42. Bruni, I.; De Mattia, F.; Galimberti, A.; Galasso, G.; Banfi, E.; Casiraghi, M.; Labra, M.; Int. J. Legal Med. 2010, 124, 595.

43. Volk, G. M.; Lynch-Holm, V. J.; Kostman, T. A.; Goss, L. J.; Franceschi, V. R.; Plant Biol. 2002, 4, 34.

44. Waller, G. R.; Nowacki, E. K.; Alkaloid biology and metabolism in plants, Springer: New York, 1978.

45. Robinson, T.; Science 1974, 184, 430.

46. Colombo, M. L.; Assisi, F.; Puppa, T. Della; Moro, P.; Sesana, F. M.; Bissoli, M.; Borghini, R.; Perego, S.; Galasso, G.; Banfi, E.; Davanzo, F.; J. Pharm. Sci. Res. 2010, 2, 417.

47. Glatstein, M.; Alabdulrazzaq, F.; Scolnik, D.; Am. J. Ther. 2016, 23 , e74.

48. Dickel, O. E.; Aguiar, R. B. de; Geracitano, L.; Monserrat, J. M.; Barros, D. M.; Rev. Bras. Farm. 2010, 91, 189.

49. Alves, M. N.; Sartoratto, A.; Trigo, J. R.; J. Chem. Ecol. 2007, 33, 297.

50. Botha, C. J.; Penrith, M. L.; J. Ethnopharmacol. 2008, 119, 549.

51. Lehmann, K. A.; Supportive Care in Cancer 1997, 5, 439.

52. Khan, R. U.; Mehmood, S.; Khan, S. U.; Pak. J. Pharm. Sci. 2018, 31, 57.

53. Villar, D.; Ortiz Díaz, J.; Plantas Tóxicas de Interés Veterinario, $1^{\mathrm{a}}$ ed., Elsevier: New York, 2006.

54. Gonzales Gil, P.; Revista de Química 2010, 24, 11.

55. Majak, W.; J. Range Manage. 2001, 54, 494.

56. Câmara, A. C. L.; Dalcin, L.; Soto-Blanco, B.; Semina: Cienc. Agrar. 2014, 35, 1961.

57. Francisco, I. A.; Pinotti, M. H. P.; Braz. Arch. Biol. Technol. 2000, 43, 487.

58. Yakubu, M. T.; Bukoye, B. B.; Contraception 2009, 80, 308.

59. Yang, C. J.; Wang, Z. Bin; Zhu, D. L.; Yu, Y.; Lei, Y. T.; Liu, Y.; Molecules 2012, 17, 5396.

60. Kakes, P.; Biochem. Syst. Ecol. 1991, 19, 519.

61. McVann, A.; Havlik, I.; Joubert, P. H.; Monteagudo, F. S. E.; South African Med. J. 1992, 81, 139.

62. Soto-Blanco, B.; Fontenele-Neto, J. D.; Silva, D. M.; Reis, P. F. C. C.; Nóbrega, J. E.; Trop. Anim. Health Prod. 2006, 38, 451.

63. De Paula Pedroza, H.; Ferreira, M. G.; de Carvalho, J. G.; Melo, K. D. A.; Keller, K. M.; Melo, M. M.; Soto-Blanco, B.; Cienc. Rural 2015, $45,864$.

64. Szakiel, A.; Pączkowski, C.; Henry, M.; Phytochem. Rev. 2011, 10, 471.

65. Stefanowicz-Hajduk, J.; Bartoszewski, R.; Bartoszewska, S.; Kochan, K.; Adamska, A.; Kosiński, I.; Ochocka, J. R.; PLoS One 2015, 10, 1. 